\title{
Physicochemical Properties of Edible Chitosan/Hydroxypropyl Methylcellulose/Lysozyme Films Incorporated with Acidic Electrolyzed Water
}

\author{
Ewa Brychcy, ${ }^{1}$ Dominika Kulig, ${ }^{1}$ Anna Zimoch-Korzycka, ${ }^{1}$ \\ Krzysztof Marycz, ${ }^{2}$ and Andrzej Jarmoluk ${ }^{1}$ \\ ${ }^{1}$ Department of Animal Products Technology and Quality Management, Wroclaw University of Environmental and Life Sciences, \\ Chelmonskiego 37/41, 51-630 Wroclaw, Poland \\ ${ }^{2}$ Electron Microscope Laboratory, Department of Animal Hygiene and Ichthyology, Wroclaw University of Environmental and \\ Life Sciences, Kożuchowska 5B, 51-630 Wroclaw, Poland
}

Correspondence should be addressed to Ewa Brychcy; ewa.brychcy@gmail.com

Received 12 March 2015; Revised 8 June 2015; Accepted 24 June 2015

Academic Editor: Xingxun Liu

Copyright (C) 2015 Ewa Brychcy et al. This is an open access article distributed under the Creative Commons Attribution License, which permits unrestricted use, distribution, and reproduction in any medium, provided the original work is properly cited.

\begin{abstract}
The treatment with acidic electrolyzed water (AEW) is a promising disinfection method due to its effectiveness in reducing microbial population. The aim of the study was to evaluate physicochemical properties of chitosan/HPMC films incorporated with lysozyme and acidic electrolyzed water. In the composite films, decreasing film solubility and increasing concentration of sodium chloride solution and prolongation of electrolysis time were observed. Electrolysis process with sodium chloride induces spongy network of film structure. The use of AEW has not changed chemical composition of films which was proved by ${ }^{1} \mathrm{H}$ NMR, MALDITOF, and FT-IR spectroscopy. The research confirmed that electrolysis significantly improved thermomechanical properties of the examined films. The contact angle values of the films were quite similar and ranged between $56^{\circ}$ and $73^{\circ}$. The increase of salt concentration used in the electrolysis process had an impact on increasing flexibility of samples. Application of electrolyzed water in commonly used food processing systems is possible. Fusion of AEW and biopolymers may provide better integration with coated food product and multidirectional protecting effect.
\end{abstract}

\section{Introduction}

Packaging is used to maintain appropriate sensory characteristics and nutritional value of food products. It also has protective function against the adverse effect of environment during transportation and storage; additionally, it has an impact on appearance of the final product. In recent years, the application of edible films and coatings based on biopolymers like proteins, polysaccharides, and lipids has raised attention of many researchers $[1,2]$ mainly because of the fact that biodegradability of protective coatings containing natural polymers reduces the application of synthetic polymers difficult for utilisation [3]. Requirements for the packaging from natural materials depend on the characteristics of food products and their changes during production and storage
[4]. Many authors focus on modification of hydrocolloids designed to produce packaging materials with the most preferable properties and multifunctional applications $[5,6]$.

Chitosan and cellulose derivatives as hydroxypropyl methylcellulose (HPMC) are promising materials for creating edible coatings or films. HPMC is a water soluble cellulose ether hydrocolloid with good film forming characteristics. It is used as a film former, tablet binder, and coating, stabilizing, suspending, and viscosity increasing agent $[7,8]$. Cellulose derivative films are poor water vapour barriers, which are the result of the inherent hydrophilic nature of polysaccharides and cellulose derivative films' poor mechanical properties. Improving the moisture barrier would be by incorporation of hydrophobic compounds, such as fatty acids, into the cellulose ether matrix to develop a composite film [9]. 
TABLE 1: Experimental design.

\begin{tabular}{|c|c|c|c|c|c|c|c|}
\hline \multirow[b]{2}{*}{ Variants } & \multicolumn{2}{|c|}{ Variability factors } & \multicolumn{5}{|c|}{ Constant factors } \\
\hline & $\mathrm{NaCl}(\%)$ & $\begin{array}{l}\text { Electrolysis time } \\
(\mathrm{min})\end{array}$ & Chitosan (\%) & $\operatorname{HPMC}(\%)$ & Lysozyme (\%) & Glycerol (\%) & Lactic acid (\%) \\
\hline N0.001E0 & 0.001 & & & & & & \\
\hline N0.01E0 & 0.01 & 0 & & & & & \\
\hline N0.1E0 & 0.1 & & & & & & \\
\hline N0.001E5 & 0.001 & & & & & 25 (of dry & \\
\hline N0.01E5 & 0.01 & 5 & 1 & 1 & 0.2 & weight of used & 0.5 \\
\hline N0.1E5 & 0.1 & & & & & polymers) & \\
\hline N0.001E10 & 0.001 & & & & & & \\
\hline N0.01E10 & 0.01 & 10 & & & & & \\
\hline N0.1E10 & 0.1 & & & & & & \\
\hline
\end{tabular}

Chitosan is a derivative of chitin, a polysaccharide with linear chain of linked 2-acetamido-2-deoxy-D-glucopyranose units. This material is biodegradable, biocompatible, and nontoxic. Due to its film forming properties and multiple uses in applications of coatings production, drug delivery, nutrients, and controlled release of food ingredients and separation techniques, it is a valuable polymer [10]. It has a high modulus along with low elongation at break owing to the high glass transition temperature $(\mathrm{Tg})$ and crystallinity. Therefore, mixing or copolymerizing chitosan with different polymers can influence its morphology and plasticity [11].

Edible films are not good barriers against water vapour; however, they could be used as a carrier of active compounds, antimicrobial agents, or preservatives, which protect food quality [12]. Such active ingredients of edible films can be lysozyme or acidic electrolyzed water.

Lysozyme is muramidase ( $\mathrm{N}$-acetyl-muramyl-hydrolase) which decomposes $\beta$-1,4-glycosidic linkage between $\mathrm{N}$ acetylmuramic acid and $\mathrm{N}$-acetylglucosamine in the cell wall of polysaccharides in bacteria. It possesses lytic properties and can be applied as an antiseptic substance [13].

Acidic electrolyzed water is an antimicrobial agent generated by membrane electrolysis of sodium chloride solution. It is characterized by low $\mathrm{pH}$, high oxidation-reduction potential, and free chlorine which is a major germicidal component $[14,15]$. The free chlorine in electrolyzed acidic water is associated with a combination of hypochlorous acid and chlorine gas [15]. AEW has the advantages of nonirritating response of mucous membranes and skin tissue [16]. Acidic electrolyzed water can be also used as a component in biomolecular system, such as hydrogels. Polymer hydrogel composites have been synthesised and characterised for their application in electrochemically controlled drug release devices. Polymer hydrogels give the possibility of obtaining various advanced functional polymers. Electrosensitive hydrogels are commonly made of polyelectrolytes and an insoluble, swellable, polymer network with ionic groups [11].

To the best of our knowledge, there is no published study regarding characterization of edible films incorporated with acidic electrolyzed water. Interactions between hydrocolloids and acidic electrolyzed water could affect physicochemical properties of edible films.
Therefore the aim of the present study was to evaluate the physicochemical properties of chitosan/HPMC films incorporated with lysozyme and acidic electrolyzed water. Further investigations will be correlated with antibacterial properties of examined films and their effectiveness in food products.

\section{Materials and Methods}

2.1. Apparatus. Electrolyzed salt solutions (acidic electrolyzed water, AEW) were generated using a water generator (own design batch type generator, equipped with two titanium electrodes coated with $0.6 \mu \mathrm{m}$ layer of platinum) by membrane electrolysis of diluted salt solutions (0.001, 0.01, and $0.1 \%)$ in various time spans ( 0,5 , and 10 minutes). The diluted aqueous solutions of sodium chloride (analytical quality, $\mathrm{POCH}$ ) were added to both the anode and the cathode chambers ( $2 \mathrm{~L}$ in each chamber) of the ionizer.

2.2. Material. A low molecular weight chitosan $(\mathrm{CH})$ obtained from shrimp shells was supplied from SigmaAldrich with 20-200 cP viscosity and DD = 75-85\%; hydroxypropyl methylcellulose (HPMC) in the METHOCEL SX product was obtained from Dow Chemical Company; lysozyme isolated from hen egg whites with the $2000 \mathrm{U} / \mathrm{mg}$ activity was purchased from Ovopol Company (Poland), in addition to lactic acid (PURAC FCC 80), glycerol (analytical quality, POCH), and $80 \%$ sodium chloride (analytical quality, $\mathrm{POCH})$.

2.3. Preparation of Polymer Films. The film stock solutions were prepared by dissolving known amount of film material (chitosan, HPMC) in (non)electrolyzed sodium chloride solutions in the amount shown in Table 1 and $0.5 \%$ of lactic acid continuously stirred, using mechanic stirrer CAT R-250 (stirring rate $400 \mathrm{rpm}$ ), for 16 hours. The lysozyme solution was prepared by dissolving known amount of lysozyme in (non)electrolyzed sodium chloride solutions. Glycerol (as a plasticizer) was added to the homogenous solutions; then all the solutions were mixed together to obtain the final concentration of components presented in Table 1. The final solutions were degassed by centrifugation and poured into a 
glass Teflon coated plate of $80 \mathrm{~mm} \times 200 \mathrm{~mm}$ and dried for 72 hours. Dehydration was carried out in Binder KBF-LOC 240 chamber at $4^{\circ} \mathrm{C}$ and relative humidity of $60 \%$. Dried films were taken off and cut out for further tests.

\subsection{Film Characterization}

2.4.1. Film Solubility in Water. The analysis was performed according to the method described by Pinotti et al. [17]. The percentage of total soluble matter (\% solubility) was calculated by the following formula:

$$
\begin{aligned}
\% \text { solubility }= & \frac{\text { Initial dry weight }- \text { Final dry weight }}{\text { Initial dry weight }} \\
& \times 100 .
\end{aligned}
$$

The samples were analysed at least in triplicate.

2.4.2. Scanning Electron Microscopy (SEM). Cross section of the obtained films was performed using EVO LS 15 Zeiss scanning electron microscope. The samples were sputtered with gold for 150 s using Scancoat 6 type (Edwards, London, England) and examined using $20 \mathrm{kV}$ voltage.

2.4.3. Fourier Transform Infrared Spectroscopy (FT-IR). The ATR FT-IR method was used for each sample testing. The spectra were recorded at a resolution of $2 \mathrm{~cm}^{-1}$ by 64 scans between 450 and $4000 \mathrm{~cm}^{-1}$ in Infinity AR60 spectrometer (ATI Mattson).

2.4.4. ${ }^{1} H$ NMR Spectroscopy. The samples were then characterized by nuclear magnetic resonance (NMR) spectroscopy. The nuclear magnetic resonance measurements were performed on a Bruker Avance III. The solid-state CP MAS NMR experiments were performed using the technique of cross-polarization with magic-angle spinning. The spectra for ${ }^{13} \mathrm{C}$ and ${ }^{1} \mathrm{H}$ nuclei were obtained, respectively, at $100.61 \mathrm{MHz}$ and $400.15 \mathrm{MHz}$ frequency in a MAS BB DVT wide-band probe with $4 \mathrm{~mm}$ diameter of zirconium $\left(\mathrm{ZrO}_{2}\right)$ rotor. The isotopically labeled $L$-[1-13C]-tyrosine (Tyr) was applied in order to optimize the parameters for the CP MAS ${ }^{13} \mathrm{C} \mathrm{NMR}$ and also to attain the first-order Hartmann-Hahn matching condition. Spectroscopic parameters are as follows: for ${ }^{13} C C P$ MAS spectrum: measurement temperature: $298 \mathrm{~K}$, rotation speed: $8 \mathrm{kHz}$, relaxation time: $3 \mathrm{~s}$, pulse: $90^{\circ}$ for ${ }^{1} \mathrm{H} 4 \mu \mathrm{s}$, contact time: $2 \mathrm{~ms}$, spectral width SWH: $40 \mathrm{kHz}, \mathrm{TD}=3.5 \mathrm{k}$, and SPINAL decoupling; for ${ }^{1} H$ MAS spectrum: measurement temperature: $298 \mathrm{~K}$, rotation speed: $8 \mathrm{kHz}$, relaxation time: $2 \mathrm{~s}$, pulse: $90^{\circ}$ for ${ }^{1} \mathrm{H} 4 \mu \mathrm{s}$, spectral width SWH: $40 \mathrm{kHz}$, and $\mathrm{TD}=16 \mathrm{k}$.

2.4.5. MALDI-TOF Mass Spectrometry. The samples for the experiment were prepared by mixing $10 \mu \mathrm{L}$ of examined solution with $10 \mu \mathrm{L}$ of matrix solution (an aqueous solution of 2,5-dihydroxybenzoic acid (DHB) at a concentration of $10 \mathrm{mg} / \mathrm{mL}$ ) in Eppendorf tube with a capacity of $0.5 \mathrm{~mL}$. $2 \mu \mathrm{L}$ of the sample was placed on a measuring plate and left to evaporate the solvent. The plate was then placed in an ion source of the mass spectrometer Voyager-Elite (PerSeptive Biosystems, Framingham, CT, USA). The ionization technique which was applied was matrix assisted laser desorption/ionization (MALDI). The wavelength of the laser radiation and accelerating voltage were at $337 \mathrm{~nm}$ and $20 \mathrm{kV}$, respectively. The positive ions were subjected to registration using ion time of flight (TOF) analyser with the reflection of ions (reflectron). The recorded mass range varied from 300 to $3500(\mathrm{~m} / \mathrm{z})$. Mass spectrum is the sum of 200 spectra. The measurements were taken using an external mass calibration based on defined reference mixture spectrum of polyethylene glycols. Processing of spectra was carried out using Data Explorer v. 4 (Applied Biosystems, Foster City, CA, USA).

2.4.6. Dynamic Mechanical Thermal Analysis (DMTA). The tests were performed using Rheometric Scientific DMTA Mk III. The loss modulus, storage modulus, and loss tangent $(\tan \delta)$ were measured at the temperature range from $-80^{\circ} \mathrm{C}$ to $+50^{\circ} \mathrm{C}$, with heating rate $2^{\circ} \mathrm{C} / \mathrm{min}$ and frequency of $1 \mathrm{~Hz}$.

2.4.7. Contact Angle Measurements. The measurements were taken with Contact Angle Analyzer (Surface Electro Optics Company) using the sessile drop method. The drop of distilled water $(6 \mu \mathrm{L})$ was placed on the surface $\left(2 \mathrm{~cm}^{2}\right)$ of the coating sample.

2.5. Statistical Analysis. The experiments were made in triplicate. The effects of two independent categorical variables such as time of electrolysis and concentration of sodium chloride were evaluated. The obtained data were analyzed using a 2-way factor analysis of variance (ANOVA) using Statistica 10 (StatSoft, Poland). Differences between means were established by Duncan test with 5\% significance.

\section{Results and Discussion}

3.1. Film Solubility in Water. It was found out that the use of the acidic electrolyzed water significantly influences solubility of edible protective films. The films containing $0.1 \%$ sodium chloride solution after 10 minutes of electrolysis (N0.1E10) present the lowest solubility of $6 \%$ (Figure 1). The highest solubility of $44 \%$ was observed in N0.01E0 film. The decreasing film solubility with increasing concentration of sodium chloride solution and prolongation of electrolysis time were observed in composite films (Figure 1). The solubility can be adjusted to enhance the possible applications by controlling the parameters of the solvent used in film formulation [17]. Water solubility is an indicator of the film's water affinity [18]. High solubility may be an advantage for some applications. In some cases, a water-insoluble film is preferred in order to provide water resistance and improve food integrity; in other cases, edible films with high water solubility may be required [1]. The required degree of solubility of the material may be changed depending on intended applications [19].

3.2. Scanning Electron Microscopy (SEM). The scanning electron micrographs of films are shown in Figure 2. The SEM (a), (b), and (c) micrographs showed smooth, compact, and 


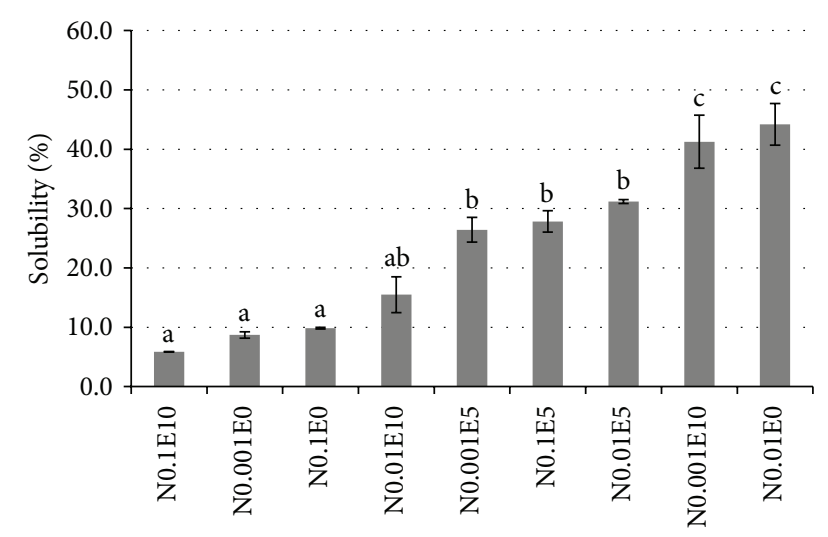

FIgURE 1: Film solubility in water. Different letters indicate significantly different groups determined by Duncan's test $(P<0.05)$.

homogeneous surface, and no pores or cracks were detected. These results are consistent with those described by Yin et al. [20], Rotta et al. [21], and de Moura et al. [22], where micrographs of cross section confirmed the partial miscibility between chitosan and HPMC. The N0.001E0 and the N0.01E5 films revealed multilayer structures, which could be associated with limited chain mobility [17]. It is related to specificity of used polymers (HPMC, chitosan, and chitooligomers) and causes differences in formation of their chains and functional groups. Electrolysis process with $\mathrm{NaCl}$ induces spongy network of film structure, which is shown in Figure 2. Process of electrolysis with $\mathrm{NaCl}$ as electrolyte causes lack of creation of crystal structure of components in LCAEW. By subjecting the electrodes to direct current voltage, two kinds of electrolyzed water with different characteristics were produced. In anode chamber of ionizer are present only chloride compounds, such as $\mathrm{Cl}_{2}, \mathrm{HOCl}, \mathrm{HCl}$, and chloride ions [15]. Sodium ions are transferred to the cathode as a result of membrane electrolysis and obtained water is not used in this study.

3.3. Fourier Transform Infrared Spectroscopy (FT-IR). The FT-IR spectra of examined films and their ingredients are shown in Figure 3. The spectrum of N0.2E30 sample shows the absorption peak at about $3232 \mathrm{~cm}^{-1}$, which is assigned to stretching vibrations from overlapping $\mathrm{O}-\mathrm{H}$ and $\mathrm{N}-\mathrm{H}$ bonds. These findings are in accordance with the results obtained by Leceta et al. [23]. The vibrations indicate interand intramolecular hydrogen bonds interaction. The signals observed at $3426 \mathrm{~cm}^{-1}, 3377 \mathrm{~cm}^{-1}, 3303 \mathrm{~cm}^{-1}$, and $2878 \mathrm{~cm}^{-1}$ were associated with $\mathrm{O}-\mathrm{H}$ stretching vibration, $\mathrm{NH}_{2}$ asymmetric stretching, $\mathrm{N}-\mathrm{H}$ stretching, and $\mathrm{C}-\mathrm{H}$ stretching, respectively. Similar peak absorption was also reported in the work of Leceta et al. [23]. Characteristic absorption bands of NAG units were observed for C-O stretching of secondary amides at $1656 \mathrm{~cm}^{-1}$ and for $\mathrm{N}-\mathrm{H}$ bending (primary amine) at $1597 \mathrm{~cm}^{-1}$. The absorption bands near $1378 \mathrm{~cm}^{-1}$ are associated with the symmetrical skeletal deformation of $\mathrm{CH}_{3}$ group and those at $1421 \mathrm{~cm}^{-1}$ with the $\mathrm{O}-\mathrm{H}$ (primary alcohol). The absorption bands at $1032 \mathrm{~cm}^{-1}$ (stretching vibration of
C-O-C ring) are characteristic for the glucopyranose ring. Praxedes et al. [24] indicated that the band peaks at $1409 \mathrm{~cm}^{-1}$ and $1316 \mathrm{~cm}^{-1}$ correspond to the vibration of $-\mathrm{OH}$ and $-\mathrm{CH}$ groups in the pyranose ring. Specific bands of $(1,4)-$ glycosidic bridges were observed at 1153 and $897 \mathrm{~cm}^{-1}$ [25, 26]. Praxedes et al. [24] observed at the peak of antisymmetric stretching C-O-C glycosidic linkage at $1080 \mathrm{~cm}^{-1}$. Many authors present different wave numbers at which there are adequate absorption bands [27]. The small band with low absorption at $1733 \mathrm{~cm}^{-1}$ refers to the acylated group $-\mathrm{OH}$ [28]. No significant differences in the positions and intensities of the bands of all the samples were observed. It means that polysaccharides were not degraded by lysozyme or acidity of electrolyzed water. Despite the fact that electrolyzed water has low $\mathrm{pH}$, basically it is a weak acid [15].

3.4. ${ }^{1} H$ NMR and ${ }^{13}$ C NMR Spectroscopy. No significant differences of intensities and widths of ${ }^{13} \mathrm{C}$ individual resonance signals for experimental films were observed (Figure 4 ). The stability of the fundamental structure of the films was proved by the lack of significant changes in ${ }^{13} \mathrm{C}$ CP MAS NMR spectra. The interactions between large amounts of protons as well as high value of their dipole coupling resulted in broadening of the proton signals in ${ }^{1} \mathrm{H}$ MAS NMR spectra. Some significant differences of ${ }^{1} \mathrm{H}$ MAS NMR spectra were noted between N0.001E0, N0.01E0, N0.001E5, N0.01E5, and N0.001E10 and N0.01E10, N0.1E0, N0.1E5, and N0.1E10 samples. The intense signal at about $4.4 \mathrm{ppm}$ was observed in spectra of N0.001E0, N0.01E0, N0.001E5, N0.01E5, and N0.01E10 films. The peak originates predominantly from water protons. Three strong signals at 5, 3.5, and $1.5 \mathrm{ppm}$ were noted. They originate from water protons or glycerol, $\mathrm{CH}$ group of chitosan and HPMC (or $\mathrm{CH}_{2}$ of glycerol), and $\mathrm{CH}_{3}$ of HPMC. Changes in intensity and width of these signals are probably correlated with different content and cross-linking structures of the films.

3.5. MALDI-TOF Mass Spectrometry. The analysis of the compounds consisting of sugar units conducted by MALDI enables the observation of the oligosaccharides in the molecular weight range from a few to several thousand daltons [29]. Although lysozyme was added to potentially increase antimicrobial activity, it also could cause polysaccharides hydrolysis, which was investigated by others [30]. Park et al. [31] and Zimoch-Korzycka and Jarmoluk [13] noted that lysozyme may cause polysaccharides hydrolysis and their products enhanced inhibition efficacy against many bacteria species. Therefore the research was carried out to identify potential oligomeric products of chitosan and HPMC hydrolysis. The intense peaks of matrix dominate in the mass range from 300 to $500 \mathrm{~m} / z$; therefore the mass range over $500 \mathrm{~m} / z$ was taken into account (Figure 5 ). No peaks of other $m / z$ values, which would create a series of constant mass differences between peaks, indicating the presence of oligomeric products with different composition, were reported. The optimum temperature required for the maximum activity of lysozyme proved to be $37^{\circ} \mathrm{C}$ [32]. Uncontrolled enzymatic degradation was inhibited by sample storage under cooling condition. 


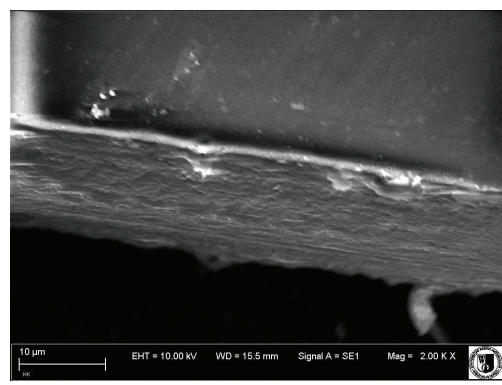

(a)

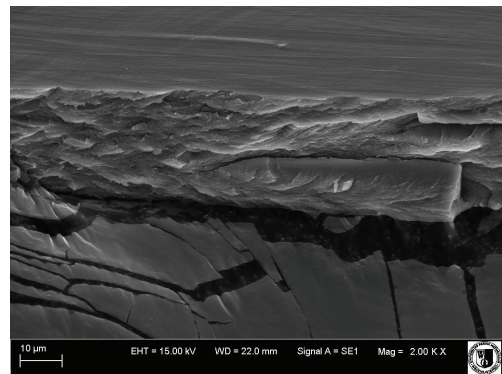

(d)

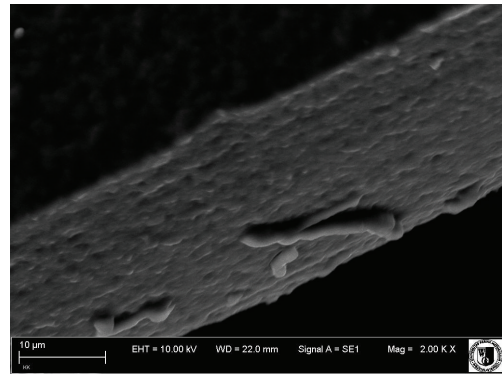

(g)

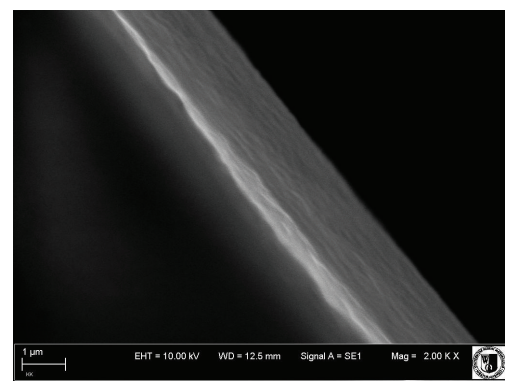

(b)

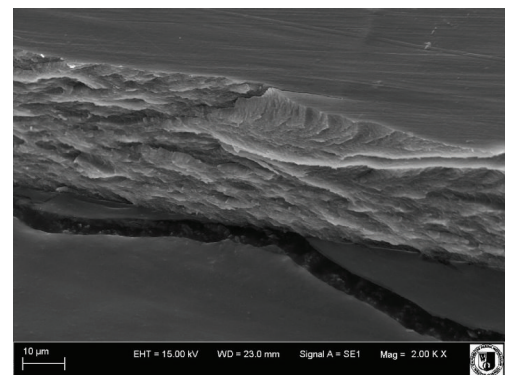

(e)

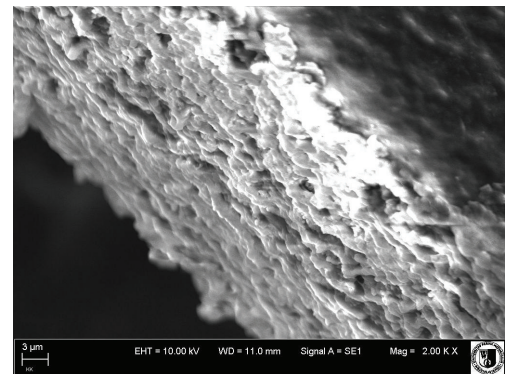

(h)

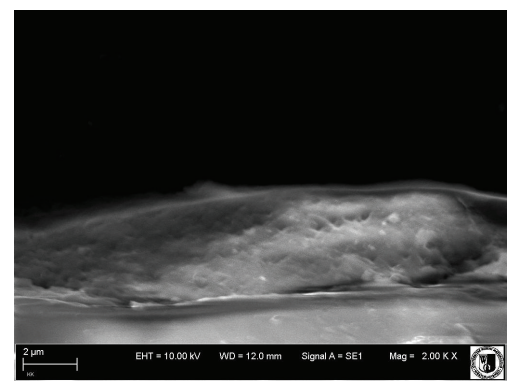

(c)

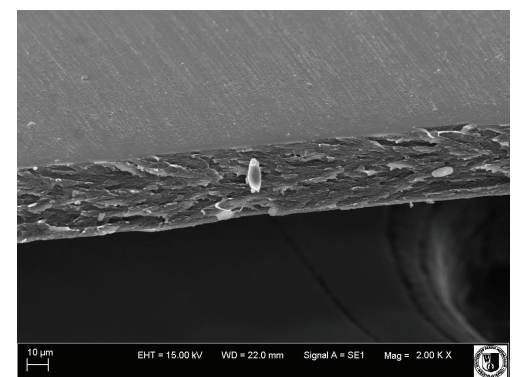

(f)

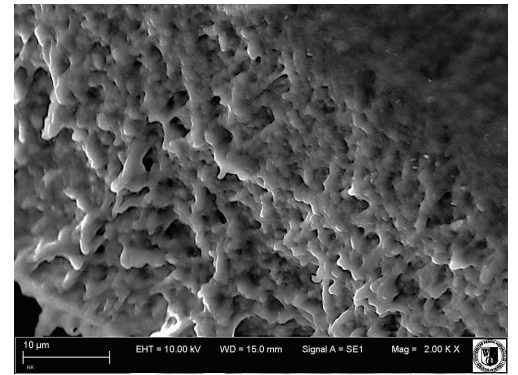

(i)

FIGURE 2: SEM micrographs of the cross section of (a) N0.001E0, (b) N0.001E5, (c) N0.001E10, (d) N0.01E0, (e) N0.01E5, (f) N0.01E10, (g) N0.1E0, (h) N0.1E5, and (i) N0.1E10 films.

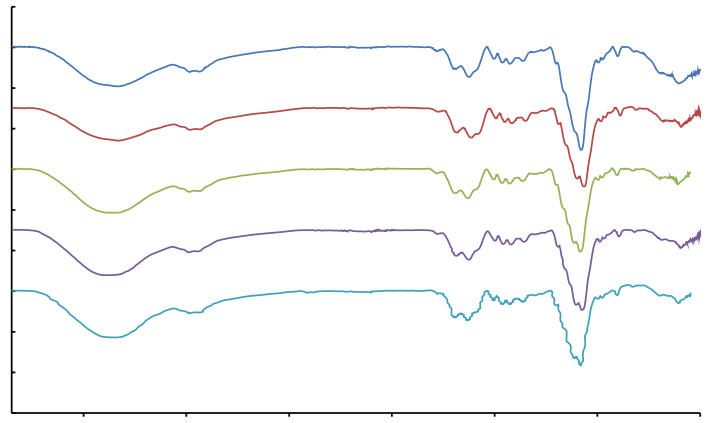

$$
\begin{aligned}
& \begin{array}{lllllll}
3450.00 & 2950.00 & 2450.00 & 1950.00 & 1450.00 & 950.00 & 450.00
\end{array} \\
& \begin{array}{ll}
\text { N0.001E0 } & - \text { N0.01E5 } \\
\text { N0.001E5 } & \text { N0.01E10 } \\
\text { N0.01E0 } &
\end{array}
\end{aligned}
$$

FIGURE 3: Spectra of Fourier Transform Infrared (FT-IR) for edible films. Reference films: N0.01E0 and N0.001E0; films incorporated with acidic electrolyzed water: N0.01E5 and N0.01E10. 


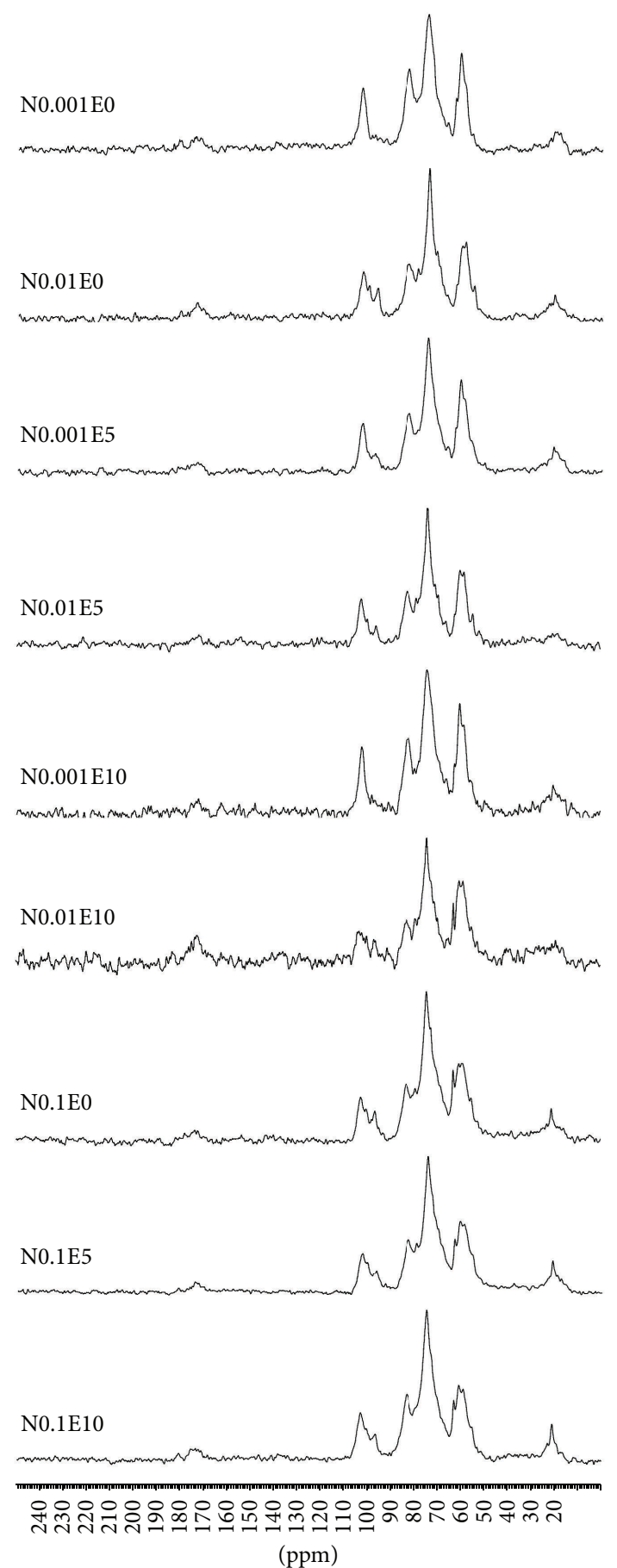

(a)

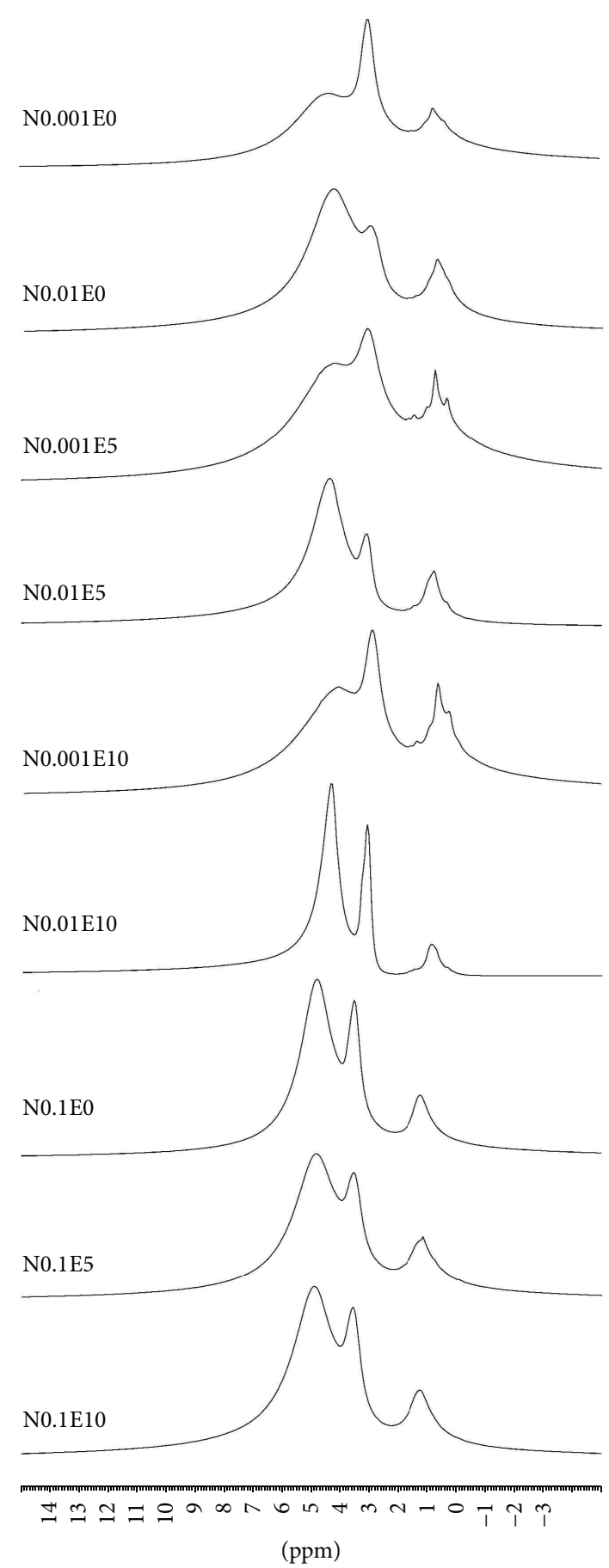

(b)

Figure $4:{ }^{13} \mathrm{C}$ NMR (a) and ${ }^{1} \mathrm{H}$ NMR (b) spectra of examined edible films.

Oligomeric products of chitosan hydrolysis were not found, which was confirmed by MALDI-TOF analysis. Chitosan degradation could lead to reduction of film homogeneity which was not desirable in this study.

3.6. Dynamic Mechanical Thermal Analysis (DMTA). Figure 6 presents the dependence on dynamic mechanical behaviour for selected films (N0.01E0, N0.01E5, N0.01E10,
N0.001E0, and N0.1E10) in order to show possible differences caused by AEW. A remarkable signal at $0^{\circ} \mathrm{C}$ for $\mathrm{N} 0.001 \mathrm{E} 0$ and N0.01E0 was noted and probably is associated with the phase transition. The analysis of N0.001E0 and N0.01E5 films showed less intense and more significant peaks at $0^{\circ} \mathrm{C}$ and $-30^{\circ} \mathrm{C}$, respectively. Sample N0.01E10 (like N0.1E10 sample) comprises the second loss tangent peak at about $0^{\circ} \mathrm{C}$. Rotta et al. [21] and Martínez-Camacho et al. [33] observed a 


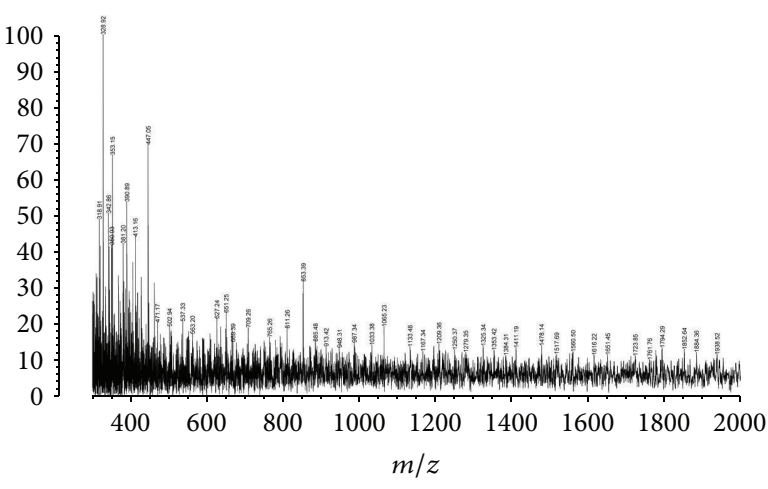

(a)

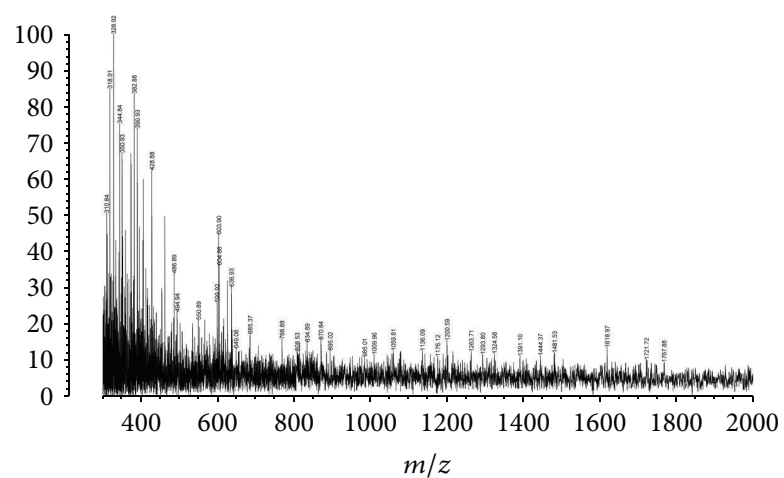

(b)

FIGURE 5: MALDI-TOF mass spectrometry analysis of edible films based on acidic electrolyzed water (N0.1E10) (a) and its reference (N0.1E0) (b).

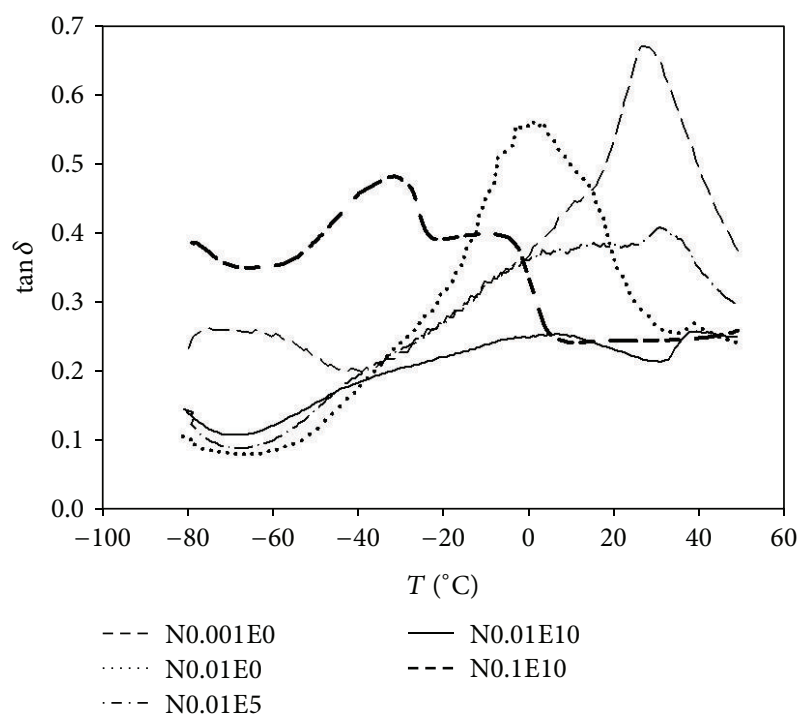

FIGURE 6: DMTA spectra of $\tan \delta$ for N0.001E0, N0.01E0, N0.01E5, N0.01E10, and N0.1E10 films.

Tg value of chitosan and hydroxypropyl methylcellulose at $203^{\circ} \mathrm{C}$ and $164^{\circ} \mathrm{C}$, respectively, whereas Kittur et al. [34] and Neto et al. [35] have not found any evidence of $\mathrm{Tg}$. The maximum in the $\tan \delta$ graph corresponds to transition temperature of the amorphous regions of the polymer $(\alpha$ relaxation) [36]. Tg is strongly dependent on both the film composition and the moisture content and can denote stability of a film. As water content of the amorphous material increases, Tg decreases. Double tangent peak was observed in N0.1E10 film, which suggests the presence of two phase transitions or weak homogeneity of the material. Two separate peaks on the graph of the loss tangent were probably associated with higher $\mathrm{NaCl}$ content. Aggregation of fillers would result in the heterogeneous collections of polymer matrix and filler. It was found that with increasing $\mathrm{NaCl}$ concentration in examined films $\alpha$ relaxation moves toward higher temperatures and its maximum is lower. The use of AEW caused a shift of the main relaxation to a higher temperature which probably indicates restricted molecular movement [37]. Close to $0^{\circ}$ loss tangent values indicate high flexibility of the sample. Process of electrolysis significantly improved thermomechanical properties of polymeric coatings. It was observed that 5-minute electrolysis improved N0.01E5 elasticity by $27.28 \%$ and elongation of electrolysis time promotes reduction of $\tan \delta$ by $54.55 \%$ compared to the untreated sample N0.01E0 $\left(0.55^{\circ}\right)$. Electrolysis process created spongy network of films, which was confirmed by SEM analysis. When the porosity of material increases, the elasticity increases also [38].

3.7. Contact Angle Measurements. The photographs of wetting films are shown in Figure 7. The study revealed that there was no significant deformation between films which contained AEW. The destruction of films is caused by dissolution of the sample by its contact with water. This process is accompanied by the formation of stress, which results in deformation of the sample. Among the tested samples N0.01E0 film was subject to insignificant deformation. There are two types of terminal groups in the chemical structure of examined films: hydrophobic methyl group $\left(-\mathrm{CH}_{3}\right)$ and hydrophilic hydroxyl group $\left(\mathrm{CH}_{3}-\mathrm{OH}\right)$. During the first phase of the analysis methyl groups were exposed to the outside, which prevented water penetration into the interior of the surface film. The tested surface of the coating was wetted with water, which probably caused its dynamic reorganization. Hydrophilic hydroxyl groups were gradually appearing on the material surface. The water drop was extended, but the penetration was insignificant. Chemical stability of N0.1E0, N0.001E5, N0.1E5, and N0.1E10 films was observed during the time of measurement. It was noted that the contact angle values of the films were quite similar and were in the range $56^{\circ}-73^{\circ}$. This evidenced insignificant differences in chemical structure surface of the test samples. Contact angles greater than $90^{\circ}$ indicate surface hydrophobicity and below $90^{\circ}$ correspond to hydrophilicity of the surface [39]. Contact angles below 90 degrees can indicate that examined films are characterized by high wettability. Park et al. [31] observed that the addition of lysozyme causes increased hydrophobic 


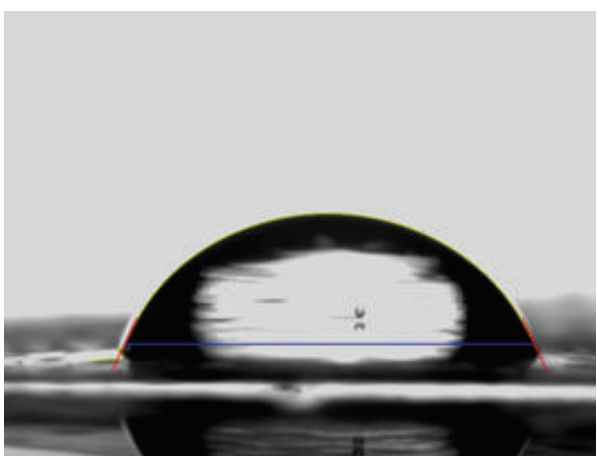

(a)

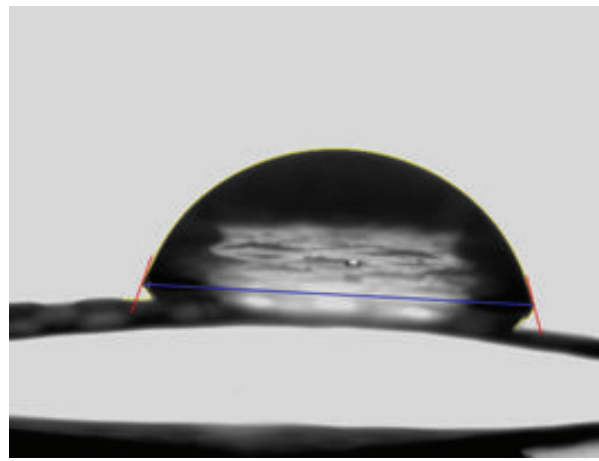

(c)

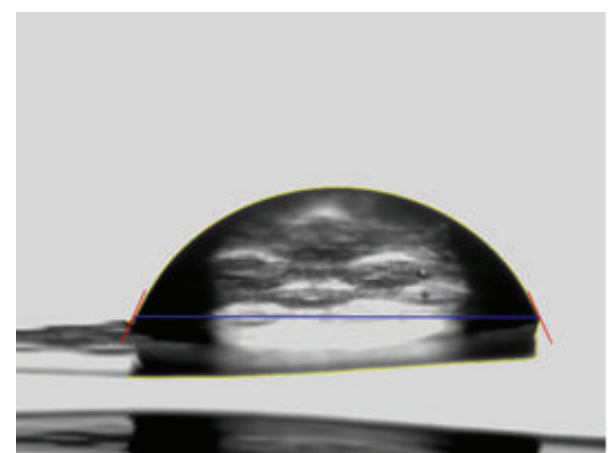

(b)

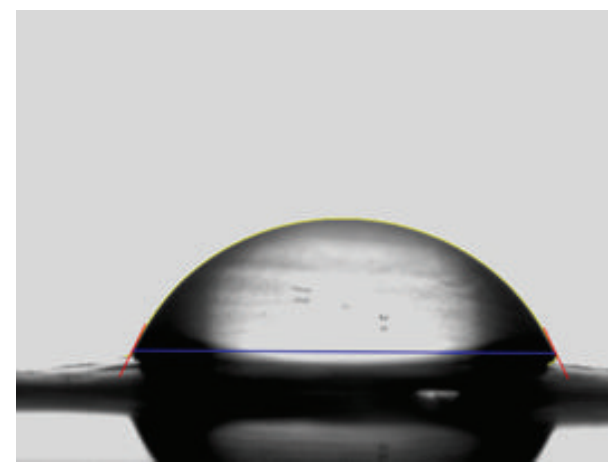

(d)

FIGURE 7: Images of contact angle for (a) N0.001E0, (b) N0.01E0, (c) N0.01E5, and (d) N0.01E10 films.

side chains in film structure and may be responsible for the decrease in hydrophilicity of lysozyme-chitosan films.

\section{Conclusions}

Control of AEW production parameters allows modifying properties of edible protective films, including their solubility and wettability, while electrolysis process improves elasticity of the polymeric films. The use of AEW has not caused undesirable changes in chemical composition of films which was proved by ${ }^{1} \mathrm{H}$ NMR, MALDI-TOF, and FT-IR analysis. The use of low salt concentration guarantees obtaining a homogeneous coating surface and desirable cohesion with all components. Application of acidic electrolyzed water generator is possible to be implemented into already existing food processing system. Fusion of AEW with biopolymers and lysozyme is easy to introduce and will provide better integration with coated food product.

\section{Conflict of Interests}

The authors declare that there is no conflict of interests regarding the publication of this paper.

\section{Acknowledgments}

This research was supported by Wroclaw Centre of Biotechnology, programme The Leading National Research Centre
(KNOW) for years 2014-2018. The authors are indebted to researchers from Centre of Molecular and Macromolecular Studies, Polish Academy of Sciences, in Lodz for their support.

\section{References}

[1] B. W. S. Souza, M. A. Cerqueira, J. A. Teixeira, and A. A. Vicente, "The use of electric fields for edible coatings and films development and production: a review," Food Engineering Reviews, vol. 2, no. 4, pp. 244-255, 2010.

[2] V. Enujiugha, R. Ayodele, and K. Seidu, "Protein-lipid films: applications in food systems," International Journal of Agriculture and Food Security, vol. 4, no. 18, pp. 553-570, 2013.

[3] K. Sztuka and I. Kołodziejska, "Jadalne folie oraz powłoki powierzchniowe $\mathrm{z}$ polimerów naturalnych stosowane do opakowań żywności," Polimery, vol. 9, pp. 625-706, 2008.

[4] S. Guilbert, N. Gontard, and L. G. M. Gorris, "Prolongation of the shelf-life of perishable food products using biodegradable films and coatings," LWT-Food Science and Technology, vol. 29, no. 1-2, pp. 10-17, 1996.

[5] M. Ye, H. Neetoo, and H. Chen, "Control of Listeria monocytogenes on ham steaks by antimicrobials incorporated into chitosan-coated plastic films," Food Microbiology, vol. 25, no. 2, pp. 260-268, 2008.

[6] M. D. R. Moreira, M. Pereda, N. E. Marcovich, and S. I. Roura, "Antimicrobial effectiveness of bioactive packaging materials from edible chitosan and casein polymers: assessment on carrot," Journal of Food Science, vol. 76, no. 1, pp. M54-M63, 2011. 
[7] F. A. Osorio, P. Molina, S. Matiacevich, J. Enrione, and O. Skurtys, "Characteristics of hydroxy propyl methyl cellulose (HPMC) based edible film developed for blueberry coatings," Procedia Food Science, vol. 1, pp. 287-293, 2011.

[8] Siddaramaiah, P. Kumar, K. Divya, B. Mhemavathi, and D. Manjula, "Chitosan/HPMC polymer blends for developing transdermal drug delivery systems," Journal of Macromolecular Science, Part A: Pure and Applied Chemistry, vol. 43, no. 3, pp. 601-607, 2006.

[9] O. Skurtys, C. Acevedo, F. Pedreschi, J. Enrione, F. Osorio, and J. Aguilera, "Food hydrocolloid edible films and coatings," Food Science and Technology, vol. 3, pp. 6-9, 2010.

[10] F. Al-Sagheer and S. Muslim, "Thermal and mechanical properties of chitosan $/ \mathrm{SiO}_{2}$ hybrid composites," Journal of Nanomaterials, vol. 2010, Article ID 490679, 7 pages, 2010.

[11] S. Kaewpirom and S. Boonsang, "Electrical response characterisation of poly(ethylene glycol) macromer (PEGM)/chitosan hydrogels in $\mathrm{NaCl}$ solution," European Polymer Journal, vol. 42, no. 7, pp. 1609-1616, 2006.

[12] R. Ahmadi, A. Kalbasi-Ashtari, A. Oromiehie, M.-S. Yarmand, and F. Jahandideh, "Development and characterization of a novel biodegradable edible film obtained from psyllium seed (Plantago ovata Forsk)," Journal of Food Engineering, vol. 109, no. 4, pp. 745-751, 2012.

[13] A. Zimoch-Korzycka and A. Jarmoluk, "The use of chitosan, lysozyme, and the nano-silver as antimicrobial ingredients of edible protective hydrosols applied into the surface of meat," Journal of Food Science and Technology, 2014.

[14] Y. Zhao, H. Xin, D. Zhao et al., "Free chlorine loss during spraying of membraneless acidic electrolyzed water and its antimicrobial effect on airborne bacteria from poultry house," Annals of Agricultural and Environmental Medicine, vol. 21, no. 2, pp. 249-255, 2014.

[15] S. Hati, S. Mandal, P. S. Minz et al., "Electrolyzed Oxidized Water (EOW): non-thermal approach for decontamination of food borne microorganisms in food industry," Food and Nutrition Sciences, vol. 03, no. 06, pp. 760-768, 2012.

[16] C.-Y. Chuang, S. Yang, H.-C. Huang et al., "Applying the membrane-less electrolyzed water spraying for inactivating bioaerosols," Aerosol and Air Quality Research, vol. 13, no. 1, pp. 350-359, 2013.

[17] A. Pinotti, M. A. García, M. N. Martino, and N. E. Zaritzky, "Study on microstructure and physical properties of composite films based on chitosan and methylcellulose," Food Hydrocolloids, vol. 21, no. 1, pp. 66-72, 2007.

[18] A. I. Bourbon, A. C. Pinheiro, M. A. Cerqueira et al., "Physicochemical characterization of chitosan-based edible films incorporating bioactive compounds of different molecular weight," Journal of Food Engineering, vol. 106, no. 2, pp. 111-118, 2011.

[19] J. Rotta, R. Á. Ozório, A. M. Kehrwald, G. M. de Oliveira Barra, R. D. de Melo Castanho Amboni, and P. L. M. Barreto, "Parameters of color, transparency, water solubility, wettability and surface free energy of chitosan/hydroxypropylmethylcellulose (HPMC) films plasticized with sorbitol," Materials Science \& Engineering C, vol. 29, no. 2, pp. 619-623, 2009.

[20] J. Yin, K. Luo, X. Chen, and V. V. Khutoryanskiy, "Miscibility studies of the blends of chitosan with some cellulose ethers," Carbohydrate Polymers, vol. 63, no. 2, pp. 238-244, 2006.

[21] J. Rotta, E. Minatti, and P. L. M. Barreto, "Determination of structural and mechanical properties, diffractometry, and thermal analysis of chitosan and hydroxypropylmethylcellulose
(HPMC) films plasticized with sorbitol," Ciência e Tecnologia de Alimentos, vol. 31, no. 2, pp. 450-455, 2011.

[22] M. R. de Moura, F. A. Aouada, R. J. Avena-Bustillos, T. H. McHugh, J. M. Krochta, and L. H. C. Mattoso, "Improved barrier and mechanical properties of novel hydroxypropyl methylcellulose edible films with chitosan/tripolyphosphate nanoparticles," Journal of Food Engineering, vol. 92, no. 4, pp. 448-453, 2009.

[23] I. Leceta, P. Guerrero, and K. de la Caba, "Functional properties of chitosan-based films," Carbohydrate Polymers, vol. 93, no. 1, pp. 339-346, 2013.

[24] A. P. P. Praxedes, A. J. C. da Silva, R. C. da Silva et al., "Effects of UV irradiation on the wettability of chitosan films containing dansyl derivatives," Journal of Colloid and Interface Science, vol. 376, no. 1, pp. 255-261, 2012.

[25] P. Gomes, C. A. R. Gomes, M. K. S. Batista, L. F. Pinto, and P. A. P. Silva, "Synthesis, structural characterization and properties of water-soluble N-( $\gamma$-propanoyl-amino acid)-chitosans," Carbohydrate Polymers, vol. 71, no. 1, pp. 54-65, 2008.

[26] G. Socrates, Infrared and Raman Characteristic Group Frequencies Tables and Charts, John Wiley \& Sons, New York, NY, USA, 3rd edition, 2001.

[27] C. Le Tien, M. Lacroix, P. Ispas-Szabo, and M.-A. Mateescu, " $N$-acylated chitosan: hydrophobic matrices for controlled drug release," Journal of Controlled Release, vol. 93, no. 1, pp. 1-13, 2003.

[28] J. Xu, S. P. McCarthy, R. A. Gross, and D. L. Kaplan, "Chitosan film acylation and effects on biodegradability," Macromolecules, vol. 29, no. 10, pp. 3436-3440, 1996.

[29] P. Mischnick, "Mass spectrometric characterization of oligoand polysaccharides and their derivatives," Advances in Polymer Science, vol. 248, pp. 105-174, 2012.

[30] A. Zimoch-Korzycka, C. Gardrat, A. Castellan, V. Coma, and A. Jarmoluk, "The use of lysozyme to prepare biologically active chitooligomers," Polímeros, vol. 25, no. 1, pp. 35-41, 2015.

[31] S.-I. Park, M. A. Daeschel, and Y. Zhao, "Functional properties of antimicrobial lysozyme-chitosan composite films," Journal of Food Science, vol. 69, no. 8, pp. M215-M221, 2004.

[32] V. Sidhan and S. Gurnani, "Kinetic characterization of rat liver nuclear lysozyme," Journal of Biosciences, vol. 4, no. 2, pp. 191195, 1982.

[33] A. P. Martínez-Camacho, M. O. Cortez-Rocha, J. M. EzquerraBrauer et al., "Chitosan composite films: thermal, structural, mechanical and antifungal properties," Carbohydrate Polymers, vol. 82, no. 2, pp. 305-315, 2010.

[34] F. S. Kittur, K. V. H. Prashanth, K. U. Sankar, and R. N. Tharanathan, "Characterization of chitin, chitosan and their carboxymethyl derivatives by differential scanning calorimetry," Carbohydrate Polymers, vol. 49, no. 2, pp. 185-193, 2002.

[35] C. G. T. Neto, J. A. Giacomettib, A. E. Jobb, F. C. Ferreirab, J. L. C. Fonsecaa, and M. R. Pereiraa, "Thermal analysis of chitosan based networks," Carbohydrate Polymers, vol. 62, no. 2, pp. 97103, 2005.

[36] T. H. Kim, J. Ahn, H. Choi, Y. Choi, and C. Cho, "A novel mucoadhesive polymer film composed of carbopol, poloxamer and hydroxypropylmethylcellulose," Archives of Pharmacal Research, vol. 30, no. 3, pp. 381-386, 2007.

[37] K. Piyada, S. Waranyou, and W. Thawien, "Mechanical, thermal and structural properties of rice starch films reinforced with rice starch nanocrystals," International Food Research Journal, vol. 20, no. 1, pp. 439-449, 2013. 
[38] A. Muscat, U. Prüße, and K.-D. Vorlop, "Stable suport materials for the immobilization of viable cells," in Immobilized Cells: Basics and Application, R. H. Wijffels, R. M. Buitelaar, C. Bucke, and J. Tramper, Eds., pp. 55-61, Elsevier Science, Amsterdam, The Netherlands, 1996.

[39] Y. Yuan and T. Lee, "Contact angle and wetting properties", in Surface Science Techniques, G. Bracco and B. Holst, Eds., pp. 334, Springer, Berlin, Germany, 2013. 

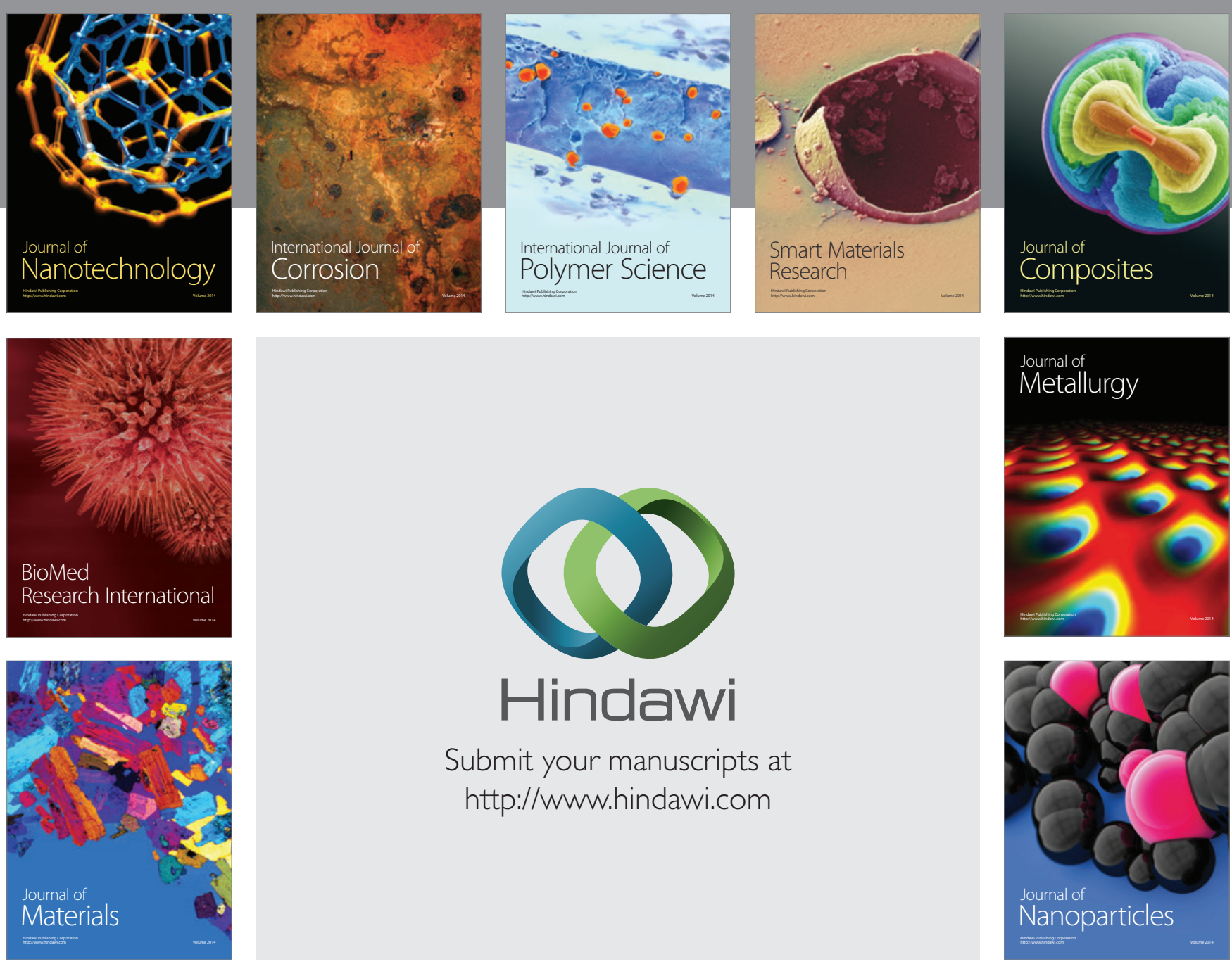

Submit your manuscripts at http://www.hindawi.com
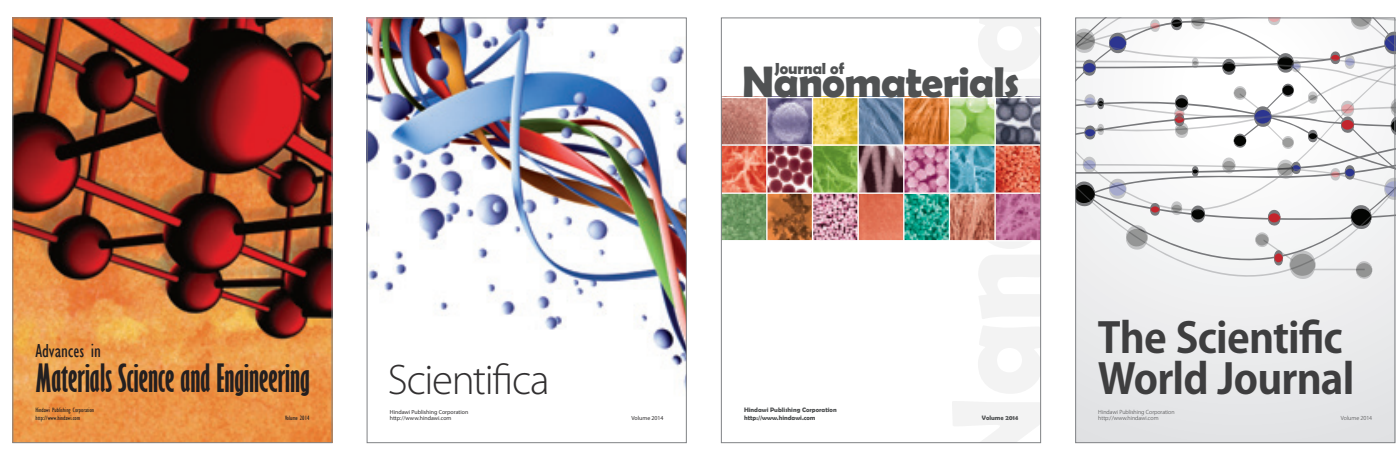

\section{The Scientific World Journal}
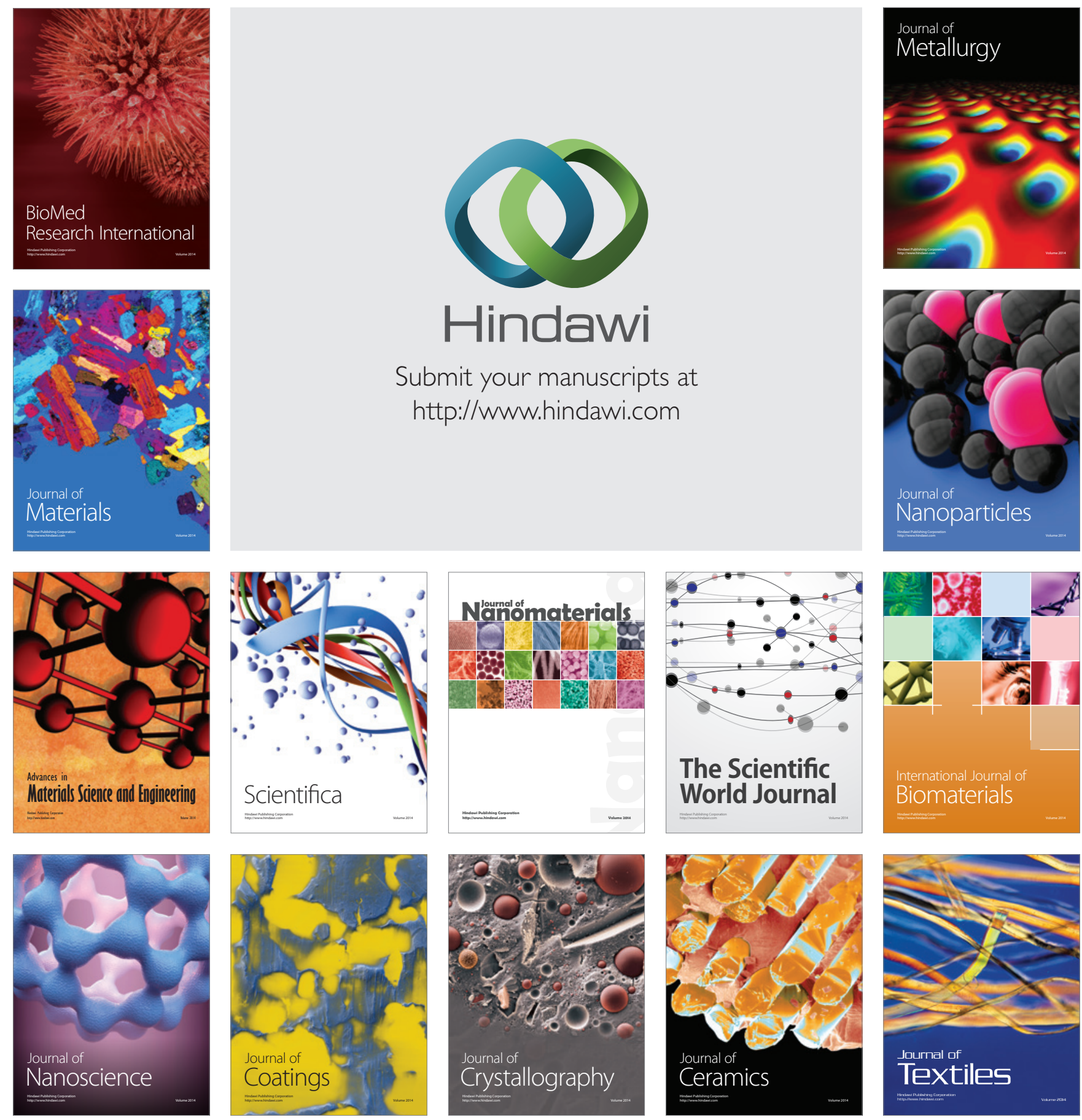